\title{
PERCEPÇÃO DE DESCONFORTO AO TOCAR E EMPURRAR CADEIRAS DE RODAS: PARÂMETROS PARA O DESIGN ERGONÔMICO
}

\author{
Jamille N. de Lima Lanutti (1); \\ Melissa Marin Vasquez (2); \\ Oscar Felipe Idarraga (3); \\ Guilherme Bertolaccini (4); \\ Fausto Orsi Medola (5); \\ Luis Carlos Paschoarelli (6)
}

(1) PPGDesign-UNESP, Doutoranda em Design

e-mail: jamille lanutti@hotmail.com

(2) PPGDesign-UNESP, Mestranda em Design

e-mail: melissamava@gmail.com

(3) Universidad Autonoma de Occidente, Designer Gráfico

e-mail: ofim26@gmail.com

(4) ) PPGDesign-UNESP, Mestrando em Design

e-mail: guilhermebertolaccini@gmail.com

(5) PPGDesign-UNESP, Doutor em Bioengenharia

e-mail: fausto.medola@faac.unesp.br

(6) PPGDesign-UNESP, Livre-docente em Design Ergonômico

e-mail: paschoarelli@faac.unesp.br

\begin{abstract}
RESUMO
Este estudo objetivou compreender a percepção de desconforto entre diferentes gêneros de usuários (homens e mulheres) para diferentes usos (condução) de cadeiras de rodas - tocar e empurrar. Participaram do estudo 14 sujeitos adultos sem experiência no uso de cadeira de rodas. Os participantes realizaram as atividades de tocar e empurrar a cadeira de rodas e depois preenchiam o protocolo eletrônico digital, especificamente elaborado para aplicação na Internet. Os resultados apontam que existem diferenças de distribuição de contato e percepção de conforto entre as interfaces (aro e manopla) e entre gêneros feminino e masculino.
\end{abstract}




\begin{abstract}
This research aims to understand the perception of discomfort among different kinds of users (men and women) in different uses - touch and push it - wheelchairs. The study included 14 adult subjects with no experience in the use of a wheelchair. Participants performed the activities of touch and pushes the wheelchair and then filled the digital electronic protocol, specifically designed for use on the Internet. The results show that there are contact distribution differences and perceived comfort between interfaces (handrim and handle) and between females and males.
\end{abstract}

\title{
1. INTRODUÇÃO
}

De acordo com o Relatório Mundial da Deficiência (WHO, et al., 2012), existem mais de 1 bilhão de pessoas que possuem algum tipo de deficiência causada por envelhecimento da população mundial, acidentes ou enfermidades crônicas (diabetes, câncer, entre outros).

Comumente, as pessoas com deficiência fazem uso de TAs, visando melhorar o desempenho nas diferentes atividades. A WHO, et al. (2008) afirma que a cadeira de rodas é a TA de uso mais frequente que melhora a mobilidade do deficiente. Aproximadamente $10 \%$ da população com deficiência no mundo, precisam de uma cadeira de rodas para locomover-se.

A cadeira de rodas manual é a fonte primaria para a mobilidade das pessoas com deficiência, não obstante podem ser difíceis de manobrar. Adicionalmente, existem no uso da cadeira de rodas lesões agudas causadas pelo uso excessivo para o usuário da cadeira de rodas e seu cuidador (KIRBY, et al. 2011). Os usuários de cadeira de rodas usam seus membros superiores para mobilizar seu peso de maneira constante. Isto pode causar lesões graves particularmente nas mãos e pulsos.

Aproximadamente $50 \%$ das pessoas usuários de cadeira de rodas, que possuem alguma disfunção na medula espinal, apresentam percepção de dor nos punhos, as quais limitam algumas de suas atividades cotidianas (WEl, et al. 2003). Além disso é importante ressaltar que, com incremento da população deficiente, amplia-se o número de cuidadores, então considerados "usuários indiretos" da cadeira de rodas. Os cuidadores tendem a estar expostos a diversas lesões - lombares e de extremidades dos membros superiores - ao facilitar a locomoção da pessoa através da cadeira de rodas (LEE, et al. 2013). Portanto, tanto usuários, como cuidadores de cadeiras de rodas, podem apresentar diferentes percepções na habilidade (manipulação, em especial) deste produto.

\section{REFERECIAL TEÓRICO}

O conforto é definido como um estado de harmonia fisiológica, psicologia e física entre o indivíduo e o ambiente (SLATER, 1985). Quando tem presença de conforto, tem ausência de desconforto, portanto "o conforto pode ser definido com a ausência de desconforto e vice-versa" (KUIJT-EVERS, 2006. p 23). O desconforto se encontra associado principalmente com a dor, cansaço e dor; e é mediado pelos fatores físicos, 
tais como a pressão da superfície da pele, o bloqueio da circulação ou a postura corporal (KUIJT-EVERS, 2006).

Avaliações subjetivas são utilizadas geralmente para avaliar atividades manuais (de manipulação) no que diz respeito ao desconforto (BOMFIM, et al., 2014; SILVA, et al., 2013). Este tipo de avaliação aplica um mapa do corpo ou da mão (figura 01), no qual é relatado em cada região os usuários percebem sensações de desconforto (KUIJTEVERS, 2006). Habitualmente se faz uso de uma escala de classificação, e Groenesteijn et al. (2004) usou uma escala de 0 (sem desconforto) a 5 (extremadamente desconfortável) que permite classificar o nível de desconforto do usuário.

Figura 1: Mapa da mão.

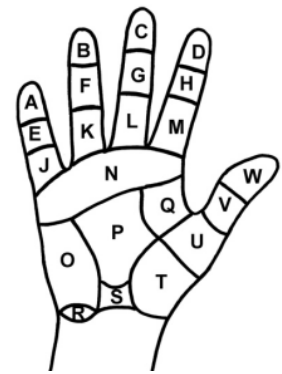

Fonte: Kuijt-Evers (2006)

Partindo do mapa da mão proposta por KUIJT-EVERS (2006) para avaliar o desconforto do usuário, foi proposto um mapa da mão dividido em 33 regiões denominadas por meio de letras (ACZ) (SILVA, et al., 2012). Este mapa de percepção de desconforto da face palmar adiciona regiões laterais desde a falange distal do dedo indicador até o polegar (Figura 02).

Figura 2: Mapeamento das mãos com letras para indicação da região palmar.

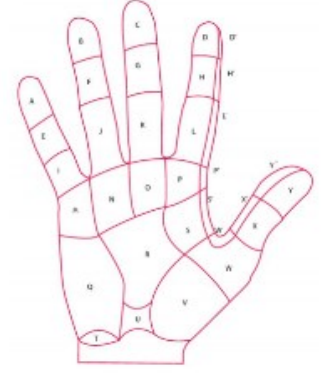

Fonte: SILVA, et al., 2012.

O método do mapa detalhado da mão permite ao designer derivar através do local da mão, onde o usuário sentiu desconforto e, portanto, a parte da empunhadura que pode estar causando a incomodidade (KUIJT-EVERS, 2006).

\section{OBJETIVO}

Este estudo tem como objetivo comparar a percepção de desconforto durante os dois usos possíveis da cadeira de rodas - tocar e empurrar - e entre diferentes gêneros de usuários: feminino e masculino. 


\section{MATERIAIS E MÉTODOS}

\subsection{Características do Estudo}

O presente estudo caracteriza-se por ser de caráter transversal exploratório, no qual foram aplicados procedimentos e instrumentos metodológicos fundamentados em raciocínio indutivo, caracterizados por uma experimentação laboratorial. Por envolver a participação de seres humanos, foi aplicado um TCLE (Termo de Consentimento Livre e Esclarecido), atendendo à Resolução 196/96-CNS-MS e à Norma ERG BR 1002, do Código de Deontologia do Ergonomista Certificado (ABERGO, 2003). O preenchimento e assinatura do participante no TCLE representava que o mesmo estava apto e aceitou sua participação.

\subsection{Participantes}

Participaram do estudo 14 sujeitos adultos, sendo sete do gênero masculino - com idade média de 25,86 anos (d.p.6,39) - e sete do gênero feminino - com idade média de 29,86 anos (d.p.4,74). Todos eram estudantes de cursos de nível superior nas áreas de humanidades (arquitetura e urbanismo, artes, design e comunicação) e nenhum dos sujeitos relatou já ter utilizado cadeira de rodas anteriormente. Esta condição foi decisiva para se obter resultados sem a possível interferência do viés da experiência de uso.

\subsection{Materiais}

Foram selecionados dois modelos de cadeiras de rodas para fazer parte do processo de avaliação de desconforto. A escolha das mesmas deu-se considerando sua morfologia. Uma das cadeiras utilizadas é do modelo Starlite da marca Ortobras (Figura 3 a), construída em alumínio aeronáutico com estrutura tipo monobloco e aro de impulso em alumínio. Considerada uma cadeira para pessoas com maior autonomia, que tenham a possibilidade de tocar a própria cadeira. E a outra cadeira de rodas, também da marca Ortobras, modelo AVD (Figura 3b) reclinável construída em alumínio aeronáutico com estrutura dobrável em $\mathrm{x}$ e aro de impulso em alumínio. Considerada uma cadeira para ser empurrada, pois o eixo de seus aros é deslocado para trás, permitindo melhor equilíbrio quando o encosto é reclinado.

Figura 3 - (a) Cadeira Starlite Ortobras; (b) Cadeira AVD Ortobras
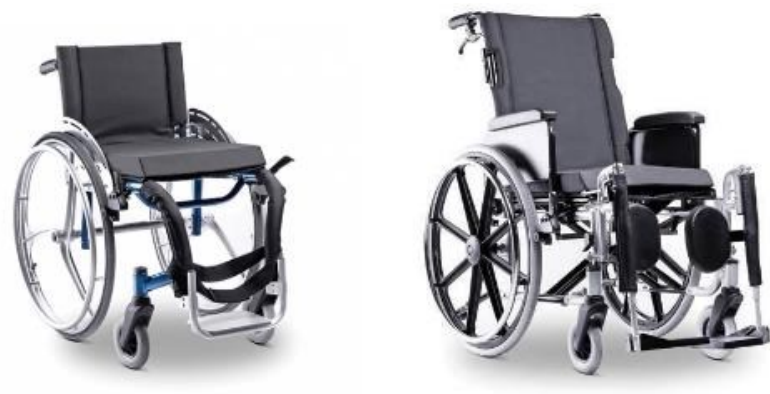

Além disso, para conhecer a massa dos sujeitos, utilizou-se uma balança eletrônica de chão. E para simular o peso dos mesmos utilizou-se anilhas para halteres com $25 \mathrm{Kg}$ ( 3 anilhas), $10 \mathrm{Kg}$ ( 2 anilhas) e $5 \mathrm{Kg}$ (2 anilhas), conforme figura 5.

Assim, foi possível a aproximação do peso dos sujeitos em até 105Kg (Figura 4). 


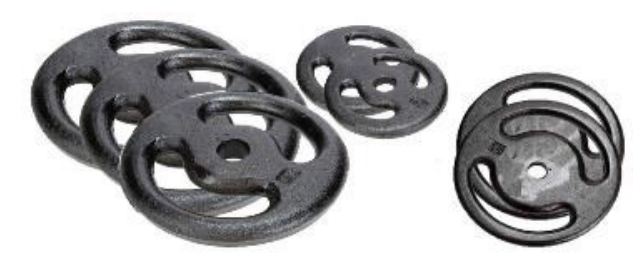

Foi desenvolvido para este estudo um protocolo eletrônico digital, especificamente elaborado para aplicação na Internet, no qual era possível aos sujeitos assinalar sobre a percepção de desconforto nas mãos.

Em seu desenvolvimento foi utilizada tecnologias de código aberto. Foram utilizados servidor web HTTP Apache, sistema de gestão de base de dados relacional MYSQL e a linguagem de programação PHP utilizado para o desenvolvimento de conteúdo dinâmico. Neste sistema, a linguagem de programação Javascript, Jquery e maphilight foi utilizada principalmente para evitar carregar a página continuamente. Além disso, utilizou-se Bootstrap para gerar a construção visual e responsiva do protocolo, que permitia interação touch screen, por utilizar maphilight js. Os dados foram coletados por meio de uma tablet Samsung Galaxy Tab de 10" (Figura 5).

Figura 5 - Interação do usuário por meio da tablet.

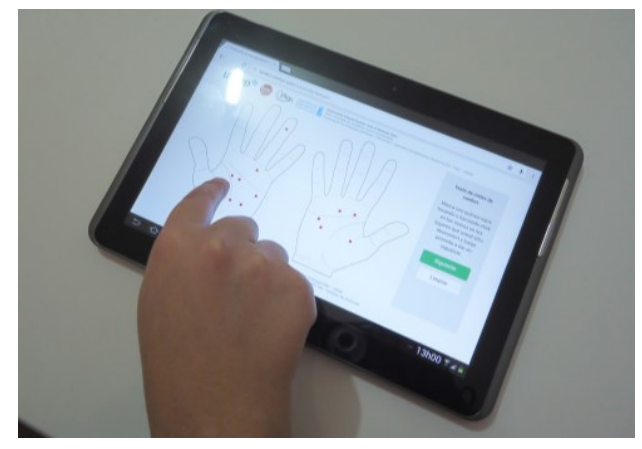

Este formulário caracterizou-se por um conjunto de telas sequenciais, com as quais 0 participante interagia tatilmente. De modo geral essas telas apresentavam numa barra superior as identidades visuais da instituição e do laboratório envolvidos no estudo, certificando a característica acadêmica do mesmo. E na parte inferior, com menor destaque o endereço do Laboratório de Ergonomia e Interfaces do PPGDesignUNESP, Campus Bauru.

A primeira sessão (Figura 6) apresenta um formulário de identificação, contendo campos para nome, naturalidade, idade, gênero, lateralidade, contatos, bem como o questionamento sobre a prática ou não de atividade física e com que frequência; e a existência ou não de sintomas musculoesqueléticos nos membros superiores e quais.

Somente com o preenchimento de todos os campos o botão 'começar' tornava-se ativo, permitindo ao participante acioná-lo para dar continuidade ao formulário. 
Figura 6 - Sessão contendo o formulário de identificação.

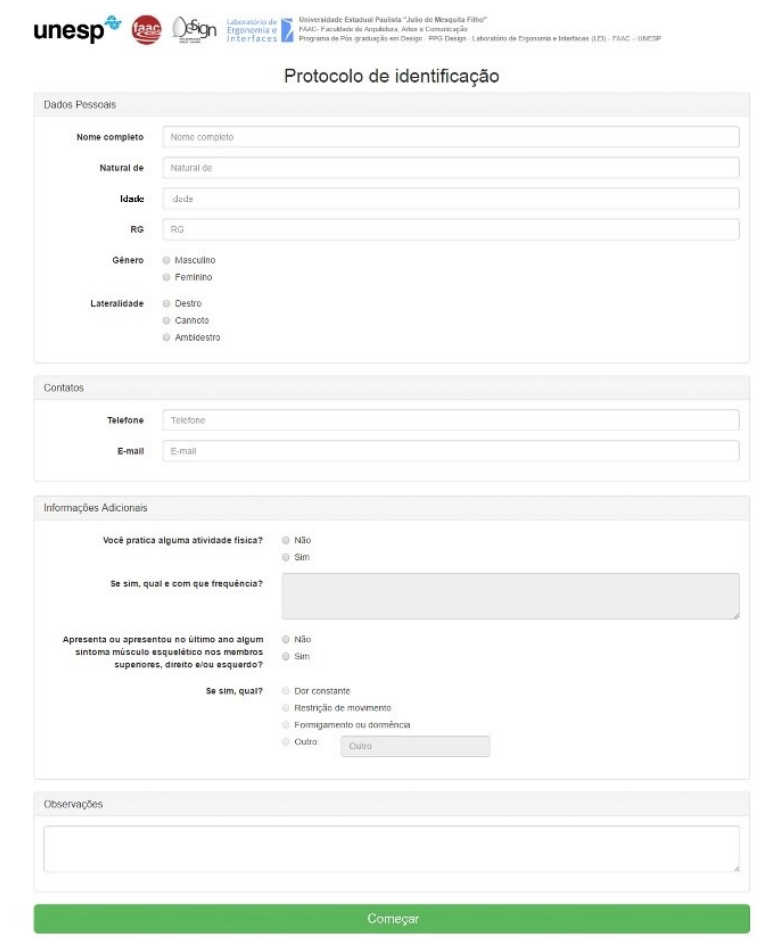

A partir da segunda sessão (Figura 7) apresentava-se imagens contendo o contorno das mãos, com indicação na lateral direita explicando que os sujeitos deveriam assinalar os locais onde perceberam desconforto, levando em consideração a atividade realizada anteriormente - tocar ou empurrar a cadeira. Dessa forma assim que tocavam a tela pontos avermelhados apareciam. Esta sessão também possuía dois botões, um que permitia aos sujeitos limpar os pontos assinalados e começar novamente a marcação, e outro destacado que permitia ir para a sessão seguinte.

Figura 7 - Sessão para assinalar os locais de percepção de desconforto.

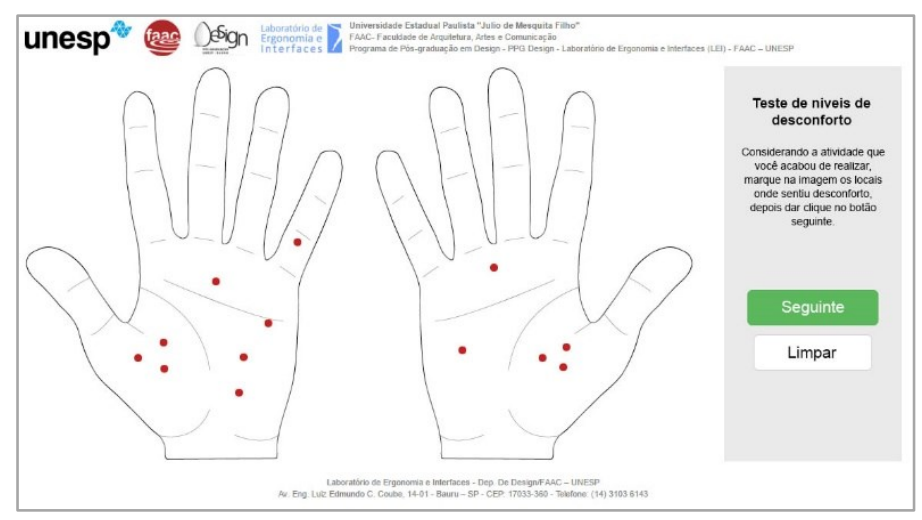

Na terceira sessão (Figura 8a) o protocolo apresentava as imagens dos contornos da mão com um mapa da mão divididas em regiões, conforme estabelecido por Silva et 
al. (2012). Na lateral direita havia instrução para que os sujeitos indicassem o nível de desconforto percebido, sendo 1 (um) a percepção de desconforto mais baixa e 5 (cinco) o mais elevado, estando destacadas e aptas para esta avaliação somente as regiões onde haviam pontos assinalados.

Assim que os sujeitos tocavam em uma das áreas em destaque, a quarta sessão (Figura 8b) surgia, apresentando na lateral direita uma escala a ser assinalada. Assim que a percepção de desconforto de cada área em destaque era classificada, esta área mudava de cor, possibilitando notar quais áreas já haviam sido avaliadas. E por fim, também na lateral direita, os sujeitos deveriam acessar o botão em destaque 'salvar' para guardar as informações do teste.

Figura 8 - (a) Sessão apresentando mapa da mão divididas em regiões; (b) Sessão para avaliação dos níveis de percepção de desconforto.

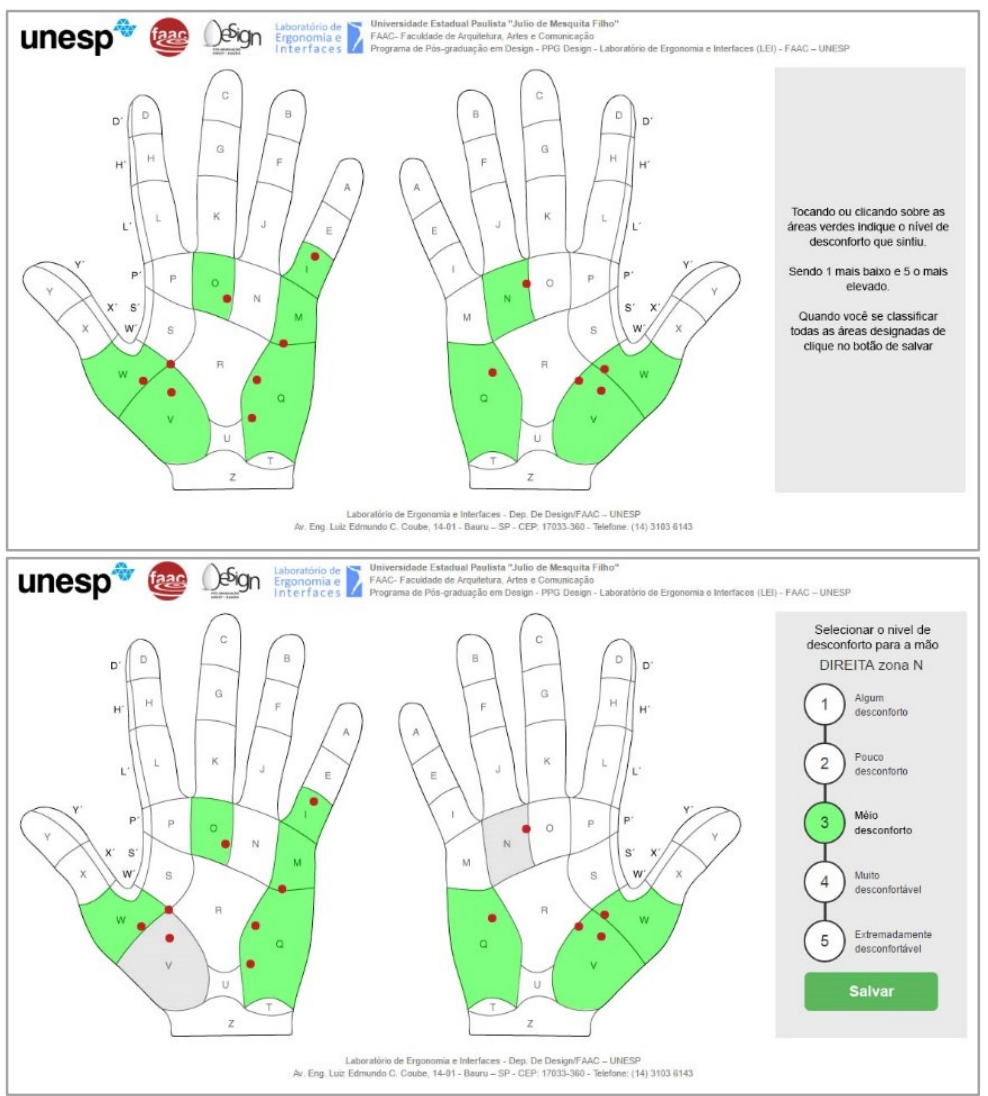

Buscando assegurar aos sujeitos que as informações foram salvas e o teste realizado efetivamente, surgia então a ultima sessão com a mensagem 'Teste realizado com sucesso' e agradecendo a participação no estudo.

Esta sessão também permitia que os pesquisadores iniciassem um novo teste por meio de um botão em destaque, ou ainda, também por meio de botões acessasse as informações dos participantes ou os registros de desconforto assinalados. 


\section{RESULTADOS}

\subsection{Resultado para a Atividade 'Empurrar a Cadeira de Rodas'}

Os resultados do desconforto percebido nas diferentes regiões da face palmar da mão para a atividade 'empurrar a cadeira de rodas' mostram que para os sujeitos do gênero masculino das 33 regiões foram assinaladas $9(27,27 \%)$ na mão esquerda e 12 $(36,36 \%)$ na mão direita, conforme apresentado na figura 9.

Figura 9 - Mapa da face palmar das mãos de indivíduos do gênero masculino para atividade 'empurrar a cadeira de rodas'.
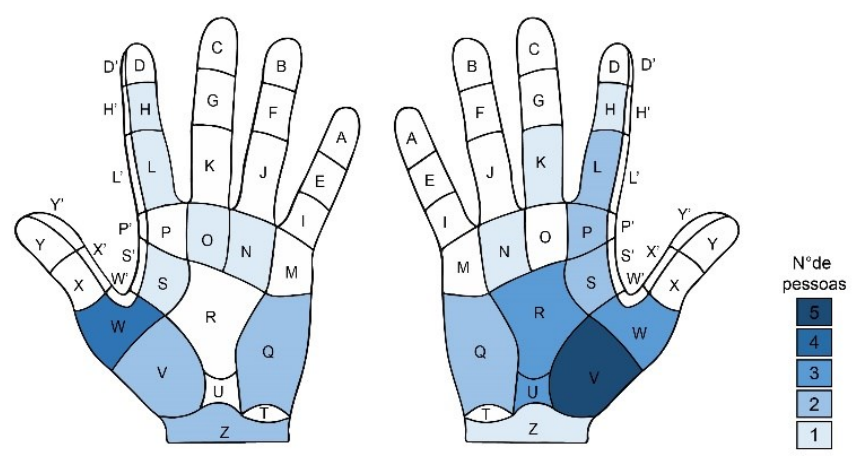

Constata-se ainda que em ambas as mãos foram assinaladas algum nível de desconforto nos dedos indicadores - principalmente nas falanges mediais e proximais - e na região palmar em ambas as mãos.

$\mathrm{Na}$ mão esquerda mais sujeitos apontaram desconforto na região metacarpal do polegar $(W)$, seguidas pelas regiões hipotenar $(V)$ e tenar $(Q)$, além da região rádioulnar (Z) e superior central (O e N).

Ocorreram mais percepções de desconforto na mão direita para a região tenar, seguidas das regiões metacarpais centrais $(R)$ e do polegar $(W)$ e da região carpal central $(U)$. Além disso, para a mão esquerda também foram assinalados desconfortos nas regiões hipotenar e da falange proximal e metacarpal do indicador (L,P e S).

Para os sujeitos do gênero feminino das 33 regiões foram assinaladas 11 (33,33\%) na mão esquerda e $24(72,72 \%)$ na mão direita, conforme apresentado na figura 10.

Figura 10 - Mapa da face palmar das mãos de indivíduos do gênero feminino para atividade 'empurrar a cadeira de rodas'.
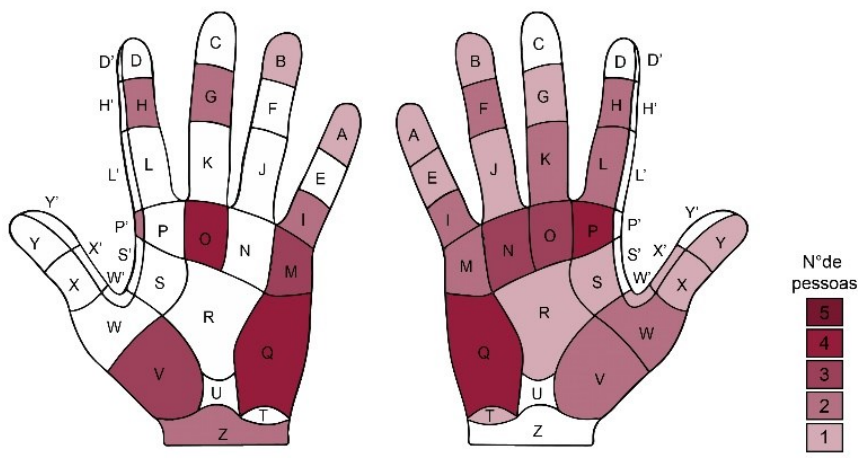
Nota-se ainda que, para este gênero, o desconforto percebido não ocorreu de forma localizada em apenas algumas regiões das mãos, tendo ocorrido apenas destaque para a região hipotênar em ambas.

$\mathrm{Na}$ mão esquerda mais pessoas relatam desconforto na região metacarpal do dedo médio $(O)$ e na região hipotênar $(Q)$, seguidas das regiões tenar $(V)$ e metacarpal do dedo mínimo $(\mathrm{M})$. Além disso, para a mão esquerda também percebeu-se desconforto nas regiões falangiais médias do indicador $(H)$ e do dedo médio $(G)$, falangial proximal do dedo mínimo (I), na lateral do metacarpo do indicador ( $\left.P^{\prime}\right)$, na região rádio-ulnar $(Z)$ e, com menor frequência de desconforto nas falanges distais dos dedos anelar (B) e mínimo $(A)$.

Quanto a mão esquerda não foram assinalados níveis de desconforto apenas na região rádio-ulnar $(Z)$ e em algumas regiões laterais. Tendo ocorrido mais percepções de desconforto nas regiões hipotênar $(Q)$ e no metacarpo do indicador $(P)$, seguidos dos metacarpos do anelar $(\mathrm{N})$ e do dedo médio $(\mathrm{O})$. Além do desconforto percebido, ainda que em com menor frequencia, na região tenar ( $\mathrm{W}$ e $\mathrm{V}$ ), nas falanges proximais e mediais de todos os dedos, nas falanges distais dos dedos mínimo, anelar e do polegar, e na região carpal $(\mathrm{T})$.

\subsection{Resultado para a Atividade 'Tocar a Cadeira de Rodas'}

Os resultados do desconforto percebido nas diferentes regiões da face palmar da mão para a atividade 'tocar a cadeira de rodas' mostram que, para os sujeitos do gênero masculino, das 33 regiões foram assinaladas $13(39,39 \%)$ na mão esquerda e 11 (33,33\%) na mão direita, conforme apresentado na figura 11.

Figura 11 - Mapa da face palmar das mãos de indivíduos do gênero masculino para atividade 'tocar a cadeira de rodas'.
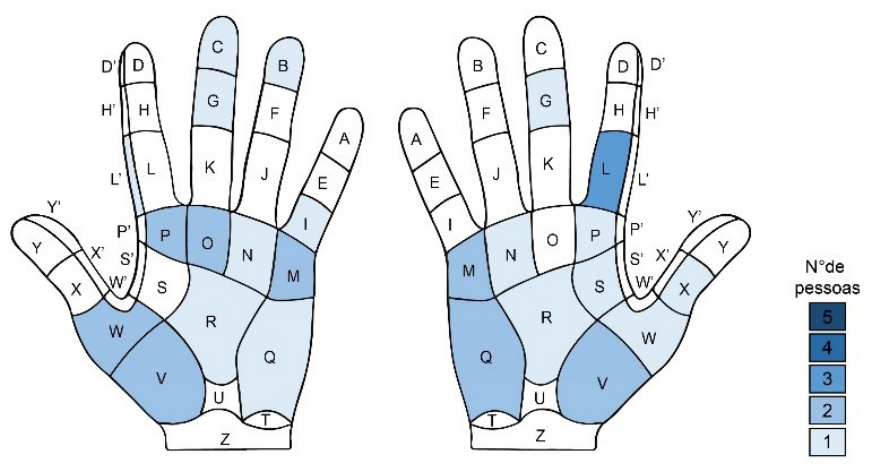

Nota-se que em ambas as mãos assinalaram-se mais regiões nas palmas das mãos, com destaque para a região tenar em ambas. Sendo que na mão esquerda não foram percebidos níveis de percepção de desconforto altos, havendo algum desconforto nas regiões metacarpais dos dedos indicador $(P)$, médio $(O)$ e mínimo $(M)$ e na região tenar ( $\mathrm{W}$ e $\mathrm{V}$ ); e frequência mínima de desconforto percebido nas regiões hipotenar, metacarpais centrais ( $N$ e R), nas falanges distais do dedo médio $(C)$ e anelar $(B)$, na falange medial do dedo médio e na lateral da falange proximal do indicador. 
Já na mão direita nota-se maior desconforto percebido na falange proximal do indicador (L), seguido da região hipotermal (V) e hipotênares ( $M$ e $Q$ ). Havendo ainda, com frequência mínima, desconforto na região falangial média do dedo médio $(G)$, metacarpal anelar $(N)$, do indicador ( $P$ e $S$ ) e central $(R)$, além da falange proximal $(X)$ e do metacarpo (W) do polegar.

Para o gênero feminino o desconforto percebido nas diferentes regiões da face palmar da mão para a atividade 'tocar a cadeira de rodas' mostram que das 33 regiões foram assinaladas $18(54,54 \%)$ na mão esquerda e 19 (57,57\%) na mão direita, conforme apresentado na figura 12 .

Figura 12 - Mapa da face palmar das mãos de indivíduos do gênero feminino para atividade 'tocar a cadeira de rodas'.
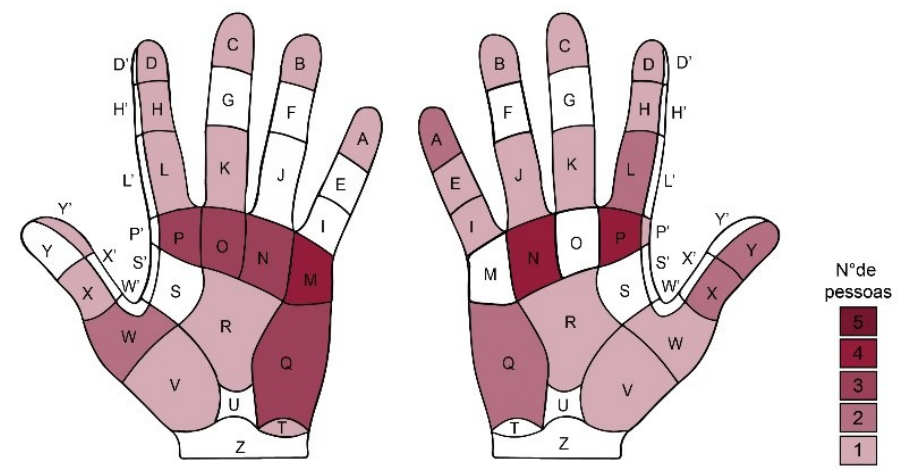

Nota-se que em ambas as mãos ocorreram mais relatos nas regiões metacarpais. $\mathrm{Na}$ mão esquerda houveram mais relatos de desconforto percebidos nas regiões metacarpais ( $W, P, O, N$ e com destaque para $N$ ), além da região hipotênar $(Q)$, havendo algum desconforto em todo o indicador $(D, H$ e $L)$, nas falanges distais $(C, B$ e $A)$, no centro da palma da mão $(R)$, na região tenar $(V)$, na falange proximal $(X)$ e na lateral da falange distal ( $\left.Y^{\prime}\right)$ do polegar.

Na mão direita, notou-se maior frequência de desconforto percebido nos metacarpos anelar $(N)$ e do indicador $(P)$, seguidos das regiões: tenar $(Q)$, falanges do polegar $(X$ e $Y$ ), metacarpo proximal do indicador $(L)$ e do metacarpo distal do dedo mínimo $(A)$. Além disso, com frequencia mínima, percebeu-se desconforto na região tenar (W e $\mathrm{V}$ ), nas falanges distais $B, C$ e $D$, nas falanges mediais dos dedos mínimo (E) e indicador $(\mathrm{H})$ e nas falanges proximais $\mathrm{I}, \mathrm{J}, \mathrm{K}$.

\section{DISCUSSÕES}

Os resultados apontam que existem diferenças de distribuição de contato e percepção de conforto entre as interfaces (manopla e aro) que permitem a empurrar ou tocar da cadeira de rodas.

$\mathrm{Na}$ percepção de conforto para ambas atividades - tocar ou empurrar a cadeira foram relatos mais regiões de desconforto para os sujeitos do gênero feminino, o que pode estar relacionado ao tamanho das mãos e a necessidade deste gênero precisar 
realizar uma pega que envolva toda a mão, por ser menor. Isto pode ser negativo por gerar desconforto até mesmo nas falanges distais, geralmente envolvidas em pegas mais finas.

Para os sujeitos do gênero masculino, notou-se maior percepção de desconforto no indicador e na região tenar para a atividade de 'empurrar', e para a atividade 'tocar' não foram apontadas grandes frequências de percepção de desconforto.

Além disso, tanto para tocar como para empurrar a cadeira de rodas, nota-se que são relatadas também mais regiões de desconforto na mão direita para ambos os gêneros. Isto provavelmente tenha ocorrido por ser a mão de dominância dos sujeitos que participaram deste estudo e, portanto, a mão que mais atua na atividade.

Para os sujeitos do gênero feminino, observa-se maiores frequências de desconforto na mão direita para a atividade 'empurrar' a cadeira, e maiores frequências de desconforto na mão esquerda para a atividade 'tocar' a cadeira.

Destaca-se ainda que, para a atividade de tocar a cadeira de rodas, as percepções de desconforto percebido foram menores e melhores distribuídas entre as mãos. Além disso, para essa atividade, não ocorreu percepção de desconforto na região rádioulnar, o que pode denotar menores exigências nas regiões dos punhos.

\section{CONSIDERAÇÕES FINAIS}

O presente estudo buscou compreender a percepção de desconforto nas mãos no uso da cadeira de rodas por meio de uma comparação de dois usos possíveis da mesma tocar e empurrar - entre diferentes gêneros.

Não foram encontrados estudos que realizaram este tipo de abordagem. $E$ isto se deve, entre outros fatores, à ausência de ferramentas (protocolos) de avaliação de percepção na face palmar da mão humana. Este estudo apresenta um aperfeiçoamento dos protocolos de percepção de conforto na face palmar da mão humana descrito por Silva et al. (2013) e traz uma contribuição efetiva para a aplicação da ergonomia na avaliação de produtos e sistemas que dependem do acionamento manual.

Além deste fator, considerando a importância do critério conforto para a interação homem-objeto e, em especial, refletindo sobre as possíveis dificuldades físicas e motoras que usuários de tecnologia assistivas podem ter, pode-se afirmar que este estudo trás reflexões e gera parâmetros de projeto relevantes.

Assim sendo, destaca-se as diferenças entre gêneros para os diferentes usos da cadeira de rodas encontrados. Ou seja, observa-se a necessidade de que produtos dessa natureza permitam maiores ajustes no que diz respeito as questões de pega. Afinal, nota-se que para os sujeitos do gênero feminino poderiam haver pegas menos robustas no que diz respeito a 'tocar a cadeira' e no que diz respeito ao gênero masculino as manoplas para 'empurrar a cadeira' poderiam se mais robustas, buscando proporcionar uma melhor distribuição de forças. 


\section{AGRADECIMENTO}

O desenvolvimento deste estudo foi possível com o apoio da CAPES.

\section{REFERÊNCIAS BIBLIOGRÁFICAS}

BONFIM, Gabriel Henrique Cruz, et al. Percepção de Desconforto na Utilização de um Produto: Ralador de Queijo. Revista Ação Ergonômica, 2014, vol. 9, no 1.

GROENESTEIJN, Liesbeth; EIKHOUT, Sandra M.; VINK, Peter. One set of pliers for more tasks in installation work: the effects on (dis) comfort and productivity. Applied ergonomics, 2004, 35.5: 485-492.

HOGETOP, Luisa; SANTAROSA, Lucila. Tecnologias assistivas: viabilizando a acessibilidade ao potencial individual. Informática na educação: teoria \& prática, 2002, vol. 5 , no 2 .

KIRBY, R. Lee, et al. The manual wheelchair-handling skills of caregivers and the effect of training. Archives of Physical Medicine and Rehabilitation, 2004, vol. 85, no 12, p. 2011-2019.

KUIJT-EVERS, L. F. M.; EIKHOUT, S. M. Development process of a new masoner's trowel. In: IEA2006: 16th World Congress on Ergonomics. 2006.

LEE, Sang-Yeol, et al. Comparison of shoulder and back muscle activation in caregivers according to various handle heights. Journal of physical therapy science, 2013, vol. 25, no 10, p. $1231-1233$.

OLIVEIRA, Luiza Maria B., et al. Cartilha do Censo 2010-Pessoas com deficiência. Brasília: Secretaria de Direitos Humanos da Presidência da República (SDH/PR), Secretaria Nacional de Promoção dos Direitos da Pessoa com Deficiência (SNPD), Coordenação-Geral do Sistema de Informações sobre a Pessoa com Deficiência, 2012.

SCHERER, M., CUSHMAN, L. Measuring subjective quality of life following spinal cord injury: a validation of assistive technology device predisposition assessment.Disability and Rehabilitation, v.23, p.387-393, 2001.

SILVA, Danilo Corrêa Silva; INOKUTI, Élen Sayuri; PASCHOARELLI, Luis Carlos. Avaliação de desconforto em atividades manuais a partir do uso de mapas da região palmar: a influência da idade. Human Factors in Design, 2013, vol. 1, no 2.

SLATER, Keith. Human Comfort. Springfield (Illinois): Charles C. Thomas, 1985

VINK, P. LOOZE, M.P; KUIJT-EVERS, L.F.M. Theory of comfort. In: Comfort in Design; principles and good practice. Vink, P. (ed.). CRC Press, 2005. Boca Raton, p.13-32.

WORLD HEALTH ORGANIZATION, et al. Pautas para el suministro de sillas de ruedas manuales en entornos de menores recursos. 2008.

WORLD HEALTH ORGANIZATION, et al. Relatório Mundial sobre a deficiencia. The World Bank. Trad Lexicus Serviços Linguísticos. São Paulo: SEDPcD, 2012.

WEl, Shun-hwa, et al. Wrist kinematic characterization of wheelchair propulsion in various 
seating positions: implication to wrist pain. Clinical Biomechanics, 2003, vol. 18, no 6, p. S46-S52. 